\title{
EDUCAÇÃO SEXUAL NA ESCOLA A PARTIR DA PSICOLOGIA HISTÓRICO-CULTURAL
}

\author{
Ana Cláudia Bortolozzi Maia* \\ Nadia Mara Eidt ${ }^{\#}$ \\ Bruna Mares Terra \\ Gabriela Lins Maia ${ }^{\mathbb{I}}$
}

\begin{abstract}
RESUMO. Este artigo relata um projeto na área da Psicologia da Educação com referencial histórico-cultural. O projeto foi desenvolvido em uma escola de ensino fundamental que teve como objetivo oferecer educação sexual para adolescentes auxiliando-os para viverem com autonomia e responsabilidade sua sexualidade. A intervenção ocorreu em 15 encontros semanais, com o uso de diferentes estratégias metodológicas abrangendo os seguintes temas: 1) Identidade Grupal e levantamento de expectativas, 2) regras de convívio grupal, 3) Conceito de Sexualidade; 4) Conceito social de adolescência, 5) Fisiologia e saúde, 6) Saúde Sexual e reprodutiva, 7) Iniciação Sexual, 8) Gravidez na Adolescência, 9) Violência Sexual, 10) Padrões de Beleza e atitudes de discriminação e 11) Gênero e diversidade sexual. Alunos e professores avaliaram a proposta de intervenção como satisfatória e necessária na escola. Almeja-se a continuidade do projeto com outros alunos e oferecer formação aos professores.
\end{abstract}

Palavras-chave: Sexualidade; educação; psicologia histórico-cultural.

\section{SEX EDUCATION IN SCHOOL FROM THE HISTORICAL-CULTURAL PSYCHOLOGY}

ABSTRACT. This article reports one project in the area of Educational Psychology by the historical-cultural theory. It was developed in an elementary school and aimed to provide sex education for adolescents helping them to live their sexuality in an independent and responsible way. The intervention occurred in 15 weekly meetings, with the use of different methodological strategies covering the following themes: 1) Identity of the group and survey of expectations, 2) rules of group interaction; 3) Concept of Sexuality, 4) Concept of social adolescence, 5) Physiology and Health, 6) Sexual and Reproductive Health, 7) Sexual Initiation, 8) Teenage Pregnancy, 9) Sexual Violence, 10) Standards of Beauty and attitudes of discrimination and 11) Gender and sexual diversity. Students and teachers evaluated the proposed intervention as satisfactory and needed at school. We aim to continue the project with other students and offer training to the teachers.

Key words: Sexuality; education; cultural-historical psychology.

\section{LA EDUCACIÓN SEXUAL EN LA ESCUELA CON LA PSICOLOGÍA HISTÓRICO-CULTURAL}

RESUMEN. Este artículo informa sobre un proyecto en el área de Psicología de la Educación con referencia histórica y cultural. El proyecto se desarrolló en una escuela primaria que tuvo como objetivo proporcionar educación sexual a los adolescentes para ayudarlos a vivir su sexualidad con autonomía y responsabilidad. La intervención se pasó en 15 encuentros semanales, con el uso de diferentes estrategias metodológicas en respecto a los siguientes temas: 1) La identidad grupal y el levantamiento de las expectativas, 2) Las reglas de la interacción del grupo, 3) El concepto de la sexualidad, 4) El concepto social de la adolescencia, 5) La fisiología y la salud, 6) Salud Sexual y Reproductiva, 7) Iniciación Sexual 8) Embarazo en Adolescentes, 9) La violencia

Doutora em Educação pela Unesp/Marília; pós-doutora pela Unesp/Araraquara; docente do curso de Psicologia da Faculdade de Ciências da Universidade Estadual Paulista Júlio de Mesquita Filho (Unesp/Bauru), Brasil.

\# Doutora em Educação Escolar pela Unesp/Araraquara; docente do curso de Psicologia da Faculdade de Ciências da Universidade Estadual Paulista Júlio de Mesquita Filho (Unesp/Bauru), Brasil.

II Discente do curso de Psicologia da Faculdade de Ciências da Universidade Estadual Paulista Júlio de Mesquita Filho (Unesp/Bauru), Brasil. 
sexual, 10) Estereotipos de belleza y las actitudes de discriminación y 11) Género y Diversidad sexual. Estudiantes y profesores evaluaron la propuesta de intervención como satisfactoria y necesaria en la escuela. Se espera la continuidad del proyecto con otros estudiantes y proporcionar formación a los docentes.

Palabras-clave: Sexualidad; la educación; la psicología histórico-cultural.

A Educação Sexual é um processo que ocorre de modo amplo e pode ser informal e assistemático ou, ainda, formal e de modo intencional (Werebe, 1998). Esse processo de educação sexual intencional é também chamado por "orientação sexual" e, nessa acepção, é entendido como um processo sistemático e continuado de intervenção, o qual deveria oferecer não apenas as informações científicas sobre sexualidade, mas proporcionar também espaços de discussão e reflexão que podem auxiliar os adolescentes a questionar mitos, tabus e preconceitos na tentativa de ajudar a escola a superar os obstáculos que se interpõem entre ela e a aprendizagem dos alunos (Brasil, 1997; Maia, 2004; Nunes \& Silva, 2000; Ribeiro, 1990; Sayão, 1997).

A escola tem sido uma das instituições privilegiadas para realizar a educação sexual. Além de ser um espaço formativo e humanizador, há como prerrogativa legal o incentivo governamental para que se ofereça nesse âmbito o esclarecimento formal sobre sexualidade - como pode ser visto no volume 10 dos Parâmetros Curriculares Nacionais (PCN) do Ensino Fundamental (Brasil, 1997).

O trabalho de educação sexual na escola vai ao encontro de uma prática da psicologia da educação comprometida com o processo de humanização. O profissional deve estar engajado com a construção de um processo educacional no qual haja a socialização do saber e da construção do pensamento crítico, de maneira que seja possível transformar o imediato em mediato, apreender a realidade em suas múltiplas determinações e entender a sociedade como um movimento de vir-a-ser (Meira, 2006).

O trabalho de educação sexual formal é fundamental para romper ideias cristalizadas $\mathrm{e}$ construídas na sociedade, formando um ser humano consciente das relações sociais a que está submetido, principalmente considerando esse ser humano no período da adolescência.

Compreende-se a adolescência como um fenômeno construído historicamente, um período de vida que não pode ser considerado independentemente do contexto social, cultural ou político no qual o indivíduo está inserido. Por sua vez, a puberdade estaria relacionada diretamente com o desenvolvimento biológico (Bock, 2004; Frota, 2007; Kahhale, 2001; Ozella \& Aguiar, 2008).
Para a Psicologia histórico-cultural, o homem é um ser de natureza social, ou seja, é candidato a humanidade, pois as disposições biológicas com as quais nasce em nada lhe garantem a vida em sociedade (Leontiev, 1978). Isso só poderá se concretizar se ele se apropriar daquilo que a humanidade já produziu - a cultura. Em outras palavras, o processo de humanização das novas gerações depende da possibilidade de apropriação, por cada indivíduo singular, das objetivações (objetos, usos e costumes) produzidas pelos seres humanos ao longo da história.

Para apropriar-se da cultura e humanizar-se, a convivência com outros indivíduos é essencial, é através dessa interação e contato que ele aprende e se torna um ser humano (Mascagna, 2009). Para desenvolver formas de relações sociais com outros homens, o indivíduo cria instrumentos, como por exemplo, a linguagem, a partir do desenvolvimento do trabalho. O ser humano, diferente dos animais, adapta a natureza e a transforma de acordo com as suas necessidades.

Esta é a marca distintiva do homem, um ser natural que se destaca da natureza, entra em contradição com ela e, para continuar existindo, precisa transformá-la. Eis a razão pela qual o que define a essência da realidade humana é o trabalho, pois é através dele que o homem age sobre a natureza, transformando-a de acordo com suas necessidades (Saviani, 2000, p. 108-109).

Ao transformar a natureza usando instrumentos e a linguagem, o homem modifica, dialeticamente, a sua própria natureza.

A linguagem é o instrumento que transmite as experiências de uma geração à outra, auxiliando em novas transformações (Cambaúva \& Silva, 2009). É também por meio da linguagem verbal e escrita que o indivíduo pode compreender o mundo, formar conceitos, inter-relacioná-los e posteriormente expressá-los por meio da fala, transmitindo esse conhecimento (Reynell \& Gruber, 1990).

Logo, a interação entre os seres humanos é essencial tanto para a sobrevivência da espécie como também para que o indivíduo possa se apropriar do saber sistematizado, do saber escolar, 
dos clássicos produzidos pela tarefa que cabe à educação escolar.

Segundo esse referencial teórico, pode-se afirmar que a Para a Psicologia Histórico-Cultural, a educação deve desenvolver no homem novas aptidões e funções psíquicas. Contudo, para que isso seja possível, é necessário que a criança se aproprie do saber sistematizado transmitido na escola. A educação, nesse contexto de transmissãoapropriação do conhecimento, engloba também a importante questão da sexualidade. É essencial a escola debater sobre esse tema já que ele é constituinte de todo ser humano e é construído durante toda a vida, manifestando-se de diferentes formas ao longo dela (Meira et al., 2006).

Ao discutir sobre o desenvolvimento das funções psíquicas na adolescência, Vigotski (1996) ressalta que nessa idade de transição não se originam novas funções elementares, pois estas são produtos de maturações orgânicas que se estabelecem juntamente com o aumento de peso do cérebro. Ao referir-se às funções superiores, considera-se como um produto do desenvolvimento cultural, histórico e social que têm magnitudes variáveis. Sendo assim, apesar da relação de dependência, as linhas de desenvolvimento histórico e biológico do indivíduo não se desenvolvem independentemente.

Surge para o adolescente um mundo com novos motivos e interesses que orientam seu comportamento a uma direção que impulsiona o pensamento à novas tarefas. Estas são as que desenvolvem a função central e lidera todo o desenvolvimento psíquico - a formação de conceitos. É a partir da formação de conceitos que ocorre o máximo da reestruturação das funções psíquicas superiores - percepção, memória, atenção e atividade prática. Os conceitos não são apenas associações relacionadas internamente, mas uma formação qualitativamente nova, um novo mecanismo intelectual no qual o conteúdo do pensamento se renova e se reestrutura (Vigotski, 1996).

Assim, se inicialmente as áreas de interesse na idade escolar são as ciências naturais, na adolescência começam a ter interesses mais abstratos como a música e a arte. É nessa idade de transição que surgem concepções sobre a vida, a sociedade, as pessoas e iniciam os questionamentos existenciais (Blonski, 1930 in Vigotski, 1996), bem como o da sexualidade humana.

Ao debater, discutir, esclarecer e tirar dúvidas sobre a temática da sexualidade, a escola faz com que os jovens possam vivê-la de modo consciente, mesmo porque o sexo não é a única forma de expressá-la, mas uma delas. $\mathrm{O}$ sujeito vive a sexualidade no âmbito individual, mas a sua construção é produzida levando em conta valores e normas sociais (Chauí, 1985; Bozon, 2004; Meira et al., 2006). O sexo é relativo aos órgãos genitais e/ou à relação sexual, enquanto a sexualidade envolve o modo de como as pessoas lidam com seus prazeres e desejos, sendo mais cultural que biológico (Louro, 1998).

Uma educação sexual ética e comprometida com a emancipação dos indivíduos deve questionar e debater os padrões de normalidade transmitidos entre as gerações e que contribuem para a naturalização de comportamentos sexuais. É preciso ressaltar que a sexualidade é uma construção social e, como tal, impõe certos padrões de como devemos nos comportar. Exemplos dessa naturalização estão nos padrões de beleza tidos como normais, que envolvem características físicas como cor da pele, do cabelo, altura e principalmente massa corporal. Outro exemplo, segundo Louro (1998), são os padrões heteronormativos que colocam a diversidade sexual como um "desvio", estimulando a discriminação entre os jovens na escola - algo bastante comum hoje em dia. Essa imposição de padrões acaba por ser algo repressivo na medida em que coloca como regra certos comportamentos em detrimento de outros (Chauí, 1985).

$\mathrm{O}$ direito dos indivíduos ao acesso à educação sexual formal e à discussão a respeito de saúde e sexualidade não deve se restringir às questões de prevenção e saúde sexual, direcionando "decisões certas" - geralmente relacionadas aos padrões sociais desejáveis. Essa educação, orientada por conhecimentos científicos acerca da temática da sexualidade, deve abranger a ludicidade, o prazer, a liberdade de viver a sexualidade (ainda que com responsabilidade) e voltadas à saúde sexual. Isto é, os conhecimentos científicos sobre a sexualidade deveriam ter caráter crítico sobre o tema, não sendo apenas de caráter biologizante e preventivo (Figueiró, 2006; Maia, 2004; Nunes \& Silva, 2000; Ribeiro, 1990).

Em consonância com a literatura consultada, o objetivo desse projeto, que integra as atividades de Estágio Supervisionado do Curso de Psicologia de uma universidade pública, foi desenvolver um projeto de educação sexual para adolescentes de uma escola municipal de uma cidade do interior paulista. Com base nas diretrizes preconizadas pelos PCN (Brasil, 1997) e outros autores da área, pretendeu-se promover reflexões e discussões entre os alunos dos sétimos 
anos escolares, com a finalidade de sistematizar a ação pedagógica da escola no trato de questões da sexualidade.

\section{DESCRIÇÃO DO DESENVOLVIMENTO DA INTERVENÇÃO}

A implementação do projeto de educação sexual foi acordado com a direção da Escola para ser realizado junto aos alunos dos sétimos anos, no horário das aulas de português. Ao todo, ocorreram 15 encontros com os estudantes, um com os pais e outro com os professores e direção, ao final do projeto.

Em um primeiro momento, foi feita uma reunião com os pais a fim de informar e obter consentimento sobre o trabalho de Educação sexual na escola. Nessa reunião houve um resgate da própria história de vida no que diz respeito à sexualidade e um convite a refleti-la. Retomando a importância de ter os conhecimentos científicos e reflexões em grupo sobre esse tema, os pais foram convidados a compartilhar as principais dificuldades que enfrentam com seus filhos quando se trata de sexualidade. Autores como Figueiró (2006), Maia (2004) e Ribeiro (1990) afirmam que é importante a participação dos pais nos projetos de educação sexual, pois eles devem acolher em casa as discussões fomentadas na escola.

Tendo como parâmetro o eixo homem-sociedade na abordagem histórico-cultural, os conteúdos dos encontros foram previamente planejados, porém, inicialmente, eles foram baseados no conhecimento cotidiano dos próprios alunos. Os encontros foram realizados a partir de temáticas norteadoras das discussões que foram pensadas de acordo com os PCN e com a literatura na área, desde que tivessem relevância sociocultural. Em cada tema levou-se em conta os aspectos psíquicos, biológicos e socioculturais da sexualidade, tendo uma visão ampla dessas questões e concebendo a sexualidade de forma científica, prazerosa e responsável. Assim, foram 11 temas trabalhados que serão descritos a seguir:

- Tema 1: Identidade grupal e levantamento de expectativas - apresentação do tema, estabelecimento de vínculo entre os participantes e levantamento de dúvidas. O objetivo foi estabelecer contato entre o facilitador e o grupo de modo positivo; conhecer o nome de cada um, possibilitando a individualização dentro do coletivo. Dúvidas foram recolhidas em uma "caixa de sugestões" anônima.

- Tema 2: Regras de convívio grupal - Construção coletiva de regras para o trabalho em grupo
(Serrão \& Baleeiro, 1999) visando o respeito na expressão de sentimentos, opiniões e dúvidas que o tema da sexualidade pode desencadear.

- Tema 3: Conceito de sexualidade ampla Esclarecimento sobre a diferença entre sexo e sexualidade para que o jovem não reduza o termo sexualidade à ato sexual, tendo a compreensão abrangente e social do tema central da intervenção (sexualidade).

- Tema 4: Conceito de adolescência - Discussão da adolescência como um fenômeno históricocultural, na compreensão de que ela foi criada pelo próprio homem dentro de um determinado contexto cultural de acordo com as necessidades que foram surgindo ao longo da história (Mascagna, 2009), em contraposição à ideia de puberdade, entendida como um fenômeno biológico e universal.

- Tema 5: Fisiologia e Saúde - Esclarecimento sobre o funcionamento fisiológico do corpo humano feminino e masculino; realização de uma atividade de sinônimos de palavras (pênis, vulva, masturbação, orgasmo e relação sexual), para conhecer o vocabulário dos alunos e oferecer os nomes corretos (Figueiró, 2006). Discussão sobre zonas erógenas e resposta sexual utilizando-se de figuras ilustrativas.

- Tema 6: Saúde sexual e reprodutiva Esclarecimento sobre menstruação, métodos contraceptivos, gestação e gravidez. Além disso, esclareceu-se sobre as doenças sexualmente transmissíveis e a prevenção ao contágio de HIV/Aids problematizando as situações de risco com o uso de histórias projetivas.

- Tema 7: Iniciação sexual - Reflexão sobre a responsabilidade do início da vida sexual que deve ocorrer de modo autônomo e consciente. Discutiu-se sobre a importância da prevenção e a relação da virgindade com as questões familiares, sociais e culturais. Ressaltou-se as diferentes formas de valorizar o sexo, a menstruação e a virgindade, nas diferentes culturas e momentos históricos.

- Tema 8: Gravidez na adolescência - Discussão da gravidez na adolescência visando preparar os jovens para a vida sexual responsável e preventiva e a autonomia de escolhas e consequências; também projetos futuros.

- Tema 9: Violência Sexual: o abuso sexual Esclarecimento sobre o conceito de abuso sexual e 
situações de violência por meio de discussão de casos fictícios.

- Tema 10: Padrões de beleza e atitudes de discriminação - Discussão sobre padrões beleza em diferentes culturas, refletindo sobre padrões de corpo e estética em diferentes períodos da história (Gregersen, 1983). Reflexão sobre a exigência atual de um padrão de beleza cultuado socialmente que pode causar discriminação social.

- Tema 11: Gênero e Diversidade Sexual Reflexão sobre os valores culturais préestabelecidos de meninos e meninas na sociedade. Discussão do gênero como uma categoria construída socialmente; apontamentos sobre a educação sexista desde a terna infância (Souza, 2006). Sensibilização sobre a homossexualidade, procurando ressaltar os padrões vigentes de heteronormatividade (Louro, 1998).

- Tema 12. Avaliação final do processo Encerramento do projeto com avaliação final. Os conteúdos foram avaliados com questões para serem respondidas como: "verdade/mentira e justificativa", esclarecendo, se necessário ainda, possíveis equívocos conceituais aos alunos.

Todo o projeto foi bem aceito na escola, especialmente por tratar de um tema que foi reconhecido por eles como algo "difícil" e que os professores não tinham preparo. Nunes e Silva (2000), Maia (2004) e Figueiró (2006) argumentam que o professor deve considerar sua própria história de educação sexual e geralmente não tem recebido preparo na sua formação acadêmica para atuar como educador sexual.

\section{CONSIDERAÇÕES FINAIS}

As propostas educacionais não estão alheias aos interesses materiais e culturais de uma sociedade e, portanto, o ideário pós-moderno está também na escola; geralmente, as escolas reforçam a visão ideológica neoliberal de homem e sociedade (Nagel, 2005; Mascagna, 2009).

Com a independência de um mediador para a aprendizagem, o individualismo se faz presente nas escolas e isso é refletido nos alunos, no caso de adolescentes, que reproduzem os comportamentos esperados na sociedade pós-moderna: consumismo, individualismo, fetiche pela mercadoria. A naturalização da adolescência faz com que se naturalizem também seus interesses. Nesse contexto, pouco se faz na direção de problematizar o processo sócio-histórico envolvido em seu desenvolvimento psíquico (Mascagna, 2009).

Durante o desenvolvimento do projeto de sexualidade junto à escola, verificou-se, por um lado, que os conceitos cotidianos trazidos pelos alunos referentes à anatomia, fisiologia e saúde - foram sendo superados por incorporação por conhecimentos científicos acerca dessas temáticas. Por outro lado, a problematização da sexualidade envolvendo aspectos sociais e culturais ampliou o universo de significações dos alunos.

O projeto de sexualidade teve o intuito de contribuir para o processo de humanização dos alunos, mediante a apropriação do conhecimento científico. A apropriação desse universo de significações possibilita a construção de um novo sentido pessoal acerca da sexualidade.

De acordo com as demandas apresentadas pelos os professores sugere-se, em continuidade, um projeto de capacitação de professores com ênfase na sexualidade instrumentalizando-os a fim de que eles também tenham um espaço de formação teóricoprática e possam dar prosseguimento ao trabalho com os adolescentes.

\section{REFERÊNCIAS}

Associação Brasileira de Enfermagem (2006). Dinâmica de sexualidade. In Associação Brasileira de Enfermagem. Revista Adolescer - compreender, atuar, colher. Recuperado em 22 set. 2010, de http://www.abennacional.org.br/revista/cap6.html.

Bock, A. M. B. (2004). A perspectiva sócio-histórica de Leontiev e a crítica à naturalização da formação do ser humano: a adolescência em questão. Cadernos Cedes, 24(62), 26-43.

Bozon, M. (2004). Sociologia da Sexualidade. Rio de Janeiro: Ed. FGV.

Cambaúva, L. G., \& Silva, L. C. (2009). A história da psicologia e a psicologia na história. In M. G. D., Facci, S. C., Tuleski, \& S. S. Barroco (Org.), Escola de Vigotski: contribuições para a Psicologia e a Educação. Maringá, PR: Eduem.

Chaú, M. (1985) Repressão sexual: essa nossa (des) conhecida. São Paulo: Brasiliense.

Figueiró, M. N. D. (2006). Educação Sexual: como ensinar no espaço da escola. Revista Linhas (UDESC), 7(1), 21.

Frota, A. M. M. C. (2007). Diferentes concepções da infância e da adolescência: A importância da historicidade para a sua construção. Estudos e Pesquisas Em Psicologia, 7(1), 144-157.

Gregersen, E. (1983). A história da sexualidade humana. São Paulo: Rocha.

Kahhale, E. M. P. (2001). Subsídios para reflexão sobre sexualidade na adolescência. In A. M. B. Bock, O. Furtado \&, M. L.T. Teixeira (Orgs.), Psicologia sóciohistórica: uma perspectiva crítica em Psicologia (pp. 179-191). São Paulo: Cortez. 
Leontiev, A. (1978). O desenvolvimento do psiquismo. Lisboa: Livros Horizonte.

Louro, G. L. (1998). Sexualidade: lições da escola. In D. E. E., Meyer (Org.), Saúde e sexualidade na escola. (Cadernos de Educação Básica, vol. 4, pp. 85-96). Porto Alegre: Mediação.

Maia, A. C. B. (2004). Orientação Sexual na escola. In P. R. M. Ribeiro (Org.), Sexualidade e Educação: aproximações necessárias (pp.153-180). São Paulo: Arte \& Ciências.

Martins, G. C. (2005). O menino que brincava de ser. (3a ed). São Paulo: DCL.

Mascagna, G. C. (2009). Adolescência: Compreensão histórica a partir da escola de Vigotski. Dissertação de Mestrado, Programa de Pós-Graduação em Psicologia, Universidade Estadual de Maringá, Maringá

Meira, M. E. M., Queiroz, A. B., Oliveira, I. A., Moraes, R. Q., \& Oliveira, T. H. (2006). Psicologia Escolar, desenvolvimento humano e sexualidade: projetos de orientação sexual em instituições educacionais. Revista Ciência em Extensão, 2(2), 21.

Ministério da Educação/Secretaria de Educação Fundamental (1997). Parâmetros Curriculares Nacionais: Orientação Sexual (vol. 10). Brasília: MEC/SEF

Nagel, L. H (2005). Educação dos alunos (ou filhos) da PósModernidade: Conselho Regional de Psicologia: Maringá-Pr.

Nunes, C., \& Silva, E. (2000). A Educação sexual da criança: subsídios teóricos e propostas práticas para uma abordagem da sexualidade além da transversalidade. Campinas, SP: Autores Associados.
Ozella, S., \& Aguiar, W. M. J. (2008). Desmistificando a concepção de adolescência. Cadernos de Pesquisa, 38(133), 97-125.

Reynell, J. K., \& Gruber, C. P. (1990). Reynell developmental language scales. Los Angeles: Western Psychological Services.

Ribeiro, P. R. M. (1990). Educação Sexual - além da informação. São Paulo: EPU.

Saviani, D. (2000). Pedagogia Histórico-Crítica - primeiras aproximações (7a ed.). Campinas, SP: Autores Associados.

Sayão, R. (1997). Orientação sexual na escola: os territórios possíveis e necessários. In A. G., Aquino (Org.), Sexualidade na escola (pp.107-117). São Paulo: Summus.

Serrão, M. \& Baleeiro, M. C. (1999). Aprendendo ser e a conviver (2a ed.). São Paulo: FTD.

Souza, F. C. (2006). Meninos e meninas na escola: um encontro possivel? Porto Alegre: Zouk.

Vigotski, L. S.(1996). Obras escogidas. Tomo IV. Madrid: Visor.

Werebe, M. J. G. (1998). Sexualidade, Política e Educação. Campinas, SP: Autores Associados.

\section{Endereço para correspondência:}

Ana Cláudia Bortolozzi Maia. Av.Eng.Luiz Edmundo Carrijo Coube, 14-01. CEP 17033-360, Bauru-SP, Brasil.E-mail: aclaudia@fc.unesp.br 